\title{
Temporal niche partitioning of Swiss black scavenger flies in relation to season and substrate age (Diptera, Sepsidae)
}

\author{
Patrick T. Rohner ${ }^{1}$, Jean-Paul Haenni ${ }^{2}$, Athene Giesen ${ }^{1}$, Juan Pablo Busso ${ }^{1}$, Martin A. Schäfer ${ }^{1}$, \\ Frank Püchel-Wieling ${ }^{2}$, Wolf U. Blanckenhorn ${ }^{1}$ \\ 1 Department of Evolutionary Biology \& Environmental Studies, University of Zurich, Winterthurerstrasse 190, CH-8057 Zürich, Switzerland \\ 2 Muséum d'histoire naturelle, Rue des Terreaux 14, 2000 Neuchâtel, Switzerland \\ 3 Biologische Station Gütersloh/Bielefeld, Niederheide 63, D-33659 Bielefeld, Germany
}

http://zoobank.org/F2727798-98DA-45A0-86F8-C828C8D3EBB3

Corresponding author: Patrick T. Rohner (patrick.rohner@uzh.ch)

\begin{abstract}
Received 3 August 2018

Accepted 19 November 2018

Published 7 January 2019

Academic editor:

Marco Moretti

\section{Key Words}

climate

distribution

Diptera

ecology

seasonality

sepsid dung flies

thermal niche

Understanding why and how multiple species manage to coexist represents a primary goal of ecological and evolutionary research. This is of particular relevance for communities that depend on resource rich ephemeral habitats that are prone to high intra- and interspecific competition. Black scavenger flies (Diptera: Sepsidae) are common and abundant acalyptrate flies associated with livestock dung decomposition in human-influenced agricultural grasslands worldwide. Several widespread sepsid species with apparently very similar ecological niches coexist in Europe, but despite their ecological role and their use in evolutionary ecological research, our understanding of their ecological niches and spatio-temporal distribution is still rudimentary. To gain a better understanding of their ecology, we here investigate niche partitioning at two temporal scales. First, we monitored the seasonal occurrence, often related to thermal preference, over multiple years and sites in Switzerland that differ in altitude. Secondly, we also investigate fine-scale temporal succession on dairy cow pastures. In accordance with their altitudinal and latitudinal distribution in Europe, some species were common over the entire season with a peak in summer, hence classified as warm-loving, whereas others were primarily present in spring or autumn. Phenological differences thus likely contribute to species coexistence throughout the season. However, the community also showed pronounced species turnover related to cow pat age. Some species colonize particularly fresh dung and are gradually replaced by others. Furthermore, the correlation between co-occurrence and phylogenetic distance of species revealed significant under-dispersion, indicating that more closely related species are frequently recovered at the same location. As a whole, our data suggests temporal niche differentiation of closely related species that likely facilitates the rather high species diversity on Swiss cattle pastures. The underlying mechanisms allowing close relatives to co-occur however require further scrutiny.
\end{abstract}

\section{Introduction}

The mechanisms driving species diversity and its persistence are of paramount interest in ecological research. In spite of longstanding and continuing scientific scrutiny, the phenomenal species diversity observed on earth, particularly within ecological guilds, remains puzzling (Tilman 1982, Levine and HilleRisLambers 2009). This is in part due to the challenges in uncovering the mechanisms driving species co-occurrence, because environmental filtering and interspecific competition (among other processes) can act in all aspects of an organism's life including what individuals eat, where and when they develop and reproduce, and what (abiotic) environmental conditions they prefer (Chesson 2000). To better understand the ecology and evolution of any species, descrip- 
tive studies of their population biology, meaning their spatio-temporal distribution and habitat preferences, are therefore indispensable.

Seasonality is a paramount environmental factor that systematically affects the population biology and distribution of organisms. Systematic latitudinal or altitudinal variation in climate and seasonality mediates prominent macro-ecological gradients that strongly contribute to the distribution of entire species assemblages (Tauber et al. 1986, Danks 1987, Addo-Bediako et al. 2000, Deutsch et al. 2008, Blanckenhorn et al. 2018, Gaston and Blackburn 2000, Gaston et al. 2008, Rohner et al. 2015, 2018, Roy et al. 2018). Such spatial patterns may affect the phenotype of co-existing species in a similar fashion, but equally often contribute to geographic species replacements along latitude or altitude (Loboda et al. 2018). In addition, species exhibit temporal, i.e. both seasonal and diurnal patterns of occurrence, which equally reflect their thermal niches and competitive interactions (e.g. Cárdenas et al. 2016). For example, the heat-sensitive yellow dung fly abounds on pastures in early spring and late autumn but largely disappears from their mating sites (dung pats) during the hottest summer months, and also shows corresponding diurnal activity patterns, being active midday on cool days but in the late afternoon on warm days (Parker 1970, Jann et al. 2000, Blanckenhorn 2009). The intrinsic physiological temperature tolerance thus underlies mostly plastic (but sometimes genetic) behavioural variation that phenomenologically gives rise to seasonal and diurnal patterns of species occurrence.

Similarly, insect communities, in particular those that inhabit ephemeral and resource rich habitats, are often characterized by pronounced species turnover (e.g. Hanski and Cambefort 1991, Jiri et al 2017). While this may be driven by environmental filtering (e.g. via diurnal patterns of activity), it can also be influenced by differences in the resources individuals forage for and how they reproduce. Such patterns of succession may help individuals evade direct competition for food and/or space by colonizing the same habitat at different times. Thus, spatio-temporal gradients, both along seasons and substrate colonization, co-define the ecological niche of closely related species that belong to the same ecological guild, and as such aid in understanding the mechanisms of species coexistence.

Closely related species are often found to be ecologically and phenotypically more similar compared to more distantly related taxa (Neeson and Mandelik 2014). Hence, the phylogenetic relationship among species can affect species interactions and community composition. If environmental filtering (e.g. via thermal adaptation) is the main driver of species assembly, closely related species are expected to co-occur more often than expected by chance because they are more likely to share an adaptation that enables them to colonize a given niche (that is, they are phylogenetically underdispersed or clustered: Webb et al. 2002). In contrast, if competition for resources is strongly limiting co-occurrence, close relatives are expected to co-occur less often than expected by chance due to competitive exclusion (i.e. they are phylogenetically overdispersed: Elton 1946, Webb et al. 2002). Incorporating the phylogenetic relationship among species can therefore aid in understanding the putative processes driving species assembly.

Black scavenger flies (Diptera: Sepsidae) are common worldwide (Ozerov 2005, Ang et al. 2013; see http://sepsidnet-rmbr.nus.edu.sg/), and are used as model organisms in a broad range of research fields ranging from classic behavioural and evolutionary ecology to developmental biology and ecotoxicology (e.g. Eberhard 2001, Bowsher and Nijhout 2007, Ingram et al. 2008, Puniamoorthy et al. 2009, 2012, 2014, Berger et al. 2013, Blanckenhorn et al. 2013, Roy et al. 2018). These flies generally depend on decaying organic matter for reproduction and larval development. There are broad differences between genera in terms of substrate specialization limiting direct competition (e.g. Orygma on rotting brown algae, Zuskamira and Ortalischema on horse dung, or Themira on waterfowl dung), but often the same species can dwell on very different sources ranging from vertebrate dung to rotting plant matter. Members of the genus Sepsis are most commonly found near livestock faeces (Pont and Meier 2002), a ubiquitous habitat in human-influenced agricultural grasslands, and hence are among the most common sepsids in Central Europe. Several widespread species of Sepsis with apparently very similar ecological niches coexist in Europe, which are somewhat, but not very clearly separated along latitude and altitude (Pont 1987, Ozerov 2005, Rohner 2015, Rohner et al. 2015). Our understanding of the spatio-temporal distribution of these closely related species is still rudimentary at the local, regional, and global scale. For example, all 12 Sepsis species occurring in Switzerland were found in a single sample from one pasture in Lenzerheide, Switzerland (Rohner et al. 2014), even though so far unpublished laboratory rearing experiments suggest direct larval resource competition between species. Based on the principle of competitive exclusion, these closely related species are expected to inhabit different diurnal, seasonal or foraging niches, facilitating their coexistence (Holt 2009, Shimadzu et al 2013). But so far, the ecological differentiation between species received little attention despite its immediate relevance for ecological and evolutionary studies (but see Püchel 1993, Bährmann and Bellstedt 2012, Jiri et al. 2017).

To further our faunistic and ecological understanding of sepsid flies in central Europe, we here systematically monitor the seasonal occurrence of the entire family over 3 years at multiple Swiss sites that differ in altitude, and complement these broad, seasonal patterns with detailed observations on species occurrence and turnover relating to cow dung age. We also investigate seasonal variation in species diversity and community structure and combine these faunistic data with information on the relatedness among species to test for phylogenetic under- or over-dispersion. If thermal adaptation contributes to temporal variation, we expect species to differ in their 
phenology, and that those taxa common at high latitudes and altitudes are more abundant in spring and/or autumn while warm adapted species should peak in summer.

\section{Materials and methods}

\section{Seasonal occurrence patterns}

Two low altitude (Siglistorf and Zürich) and two higher altitude sites (Wolzenalp and Schönenboden) with dairy cow pastures were haphazardly picked as monitoring locations for the years 2014-2016 based on convenience and proximity to people's homes (Table 1). All locations were repeatedly sampled in haphazard and uncoordinated intervals (between 2 and 5 weeks). Sampling consisted of netting ( $30 \mathrm{~cm}$ diameter) insects close to the ground by walking a transect of variable distance (between 50 and $400 \mathrm{~m}$, depending on population density) across the pasture, thus encountering old as well as fresh dung (pats). If available, dung piles next to farmhouses were additionally netted because anecdotal evidence suggests this community to be different from the one found on cattle pastures. All insects were subsequently frozen and stored in ethanol for later identification.

We additionally considered samples obtained with a malaise trap in the Swiss Jura (Le Cachot) in 1973 (Haenni and Matthey 1984; Table 1). Note that this type of collection method cannot be directly compared to the netting described above, also because this trap was not located on a cattle pasture (although a cattle pasture was only about $100 \mathrm{~m}$ distant from the trap). Nevertheless, these data still permit seasonal comparisons of relative species abundances at least within sites.

Although we counted all individuals, we only identified male sepsid flies (taxonomic authorities listed in Table 2), as females are difficult if not impossible to identify to species level (Pont and Meier 2002). Based on the number of male specimens, and assuming that this well reflects the number and distribution of females, we calculated the relative abundance of each species per sample. These relative abundances were plotted over the season. As descriptors of diversity, we used the first three Hill numbers (Hill 1973, Gotelli and Chao 2013) following:

$$
{ }^{q} D=\left(\sum_{i=1}^{s} p_{i}^{q}\right)^{\frac{1}{1-q}}
$$

where $q$ denotes the order of the Hill index. The relative influence of rare species on the diversity index decreases with $q$ in that ${ }^{0} \mathrm{D}$ equals species richness, ${ }^{1} \mathrm{D}$ represents the exponential Shannon entropy that can be interpreted as the number of typical species, while ${ }^{2} \mathrm{D}$ resembles the reciprocal form of the Gini-Simpson Index that relates to the number of highly abundant species (sensu Gotelli and Chao 2013).

Seasonal variation and differences between sampling schemes and habitat types were tested using linear mixed
Table 1. Sampling sites (all in Switzerland except Bielefeld) ordered by altitude.

\begin{tabular}{lccc}
\multicolumn{1}{c}{ Locality } & $\begin{array}{c}\text { Year } \\
\text { sampled }\end{array}$ & $\begin{array}{c}\text { Altitude } \\
(\mathbf{m})\end{array}$ & $\begin{array}{c}\text { Coordinates } \\
\text { (Lat, Long) }\end{array}$ \\
Bielefeld (D) & 1991 & $155 \mathrm{~m}$ & $52.04 \mathrm{~N}, 8.48 \mathrm{E}$ \\
Siglistorf (AG) & $2014-16$ & $440 \mathrm{~m}$ & $47.54 \mathrm{~N}, 8.38 \mathrm{E}$ \\
Ziegelhütte, Zürich (ZH) & $2014-16$ & $480 \mathrm{~m}$ & $47.40 \mathrm{~N}, 8.57 \mathrm{E}$ \\
Wolzenalp, Nesslau (SG) & $2014-16$ & $1110 \mathrm{~m}$ & $47.23 \mathrm{~N}, 9.15 \mathrm{E}$ \\
Tourbière du Cachot, Le Cachot (NE) & 1973 & $1050 \mathrm{~m}$ & $47.01 \mathrm{~N}, 6.66 \mathrm{E}$ \\
Schönenboden, Sörenberg (LU) & $2014-16$ & $1260 \mathrm{~m}$ & $46.81 \mathrm{~N}, 8.06 \mathrm{E}$ \\
\hline
\end{tabular}

models with sampling location as random effect. The effects of season (continuous variable, Julian day ranging from 1 to 365) and habitat type (dung pile versus pasture) on community composition were simultaneously analysed using a canonical correspondence analysis (with the $\mathrm{R}$ package vegan, Oksanen et al 2018). Non-metric multidimensional scaling was used to visualize seasonal community composition (as incorporated in the $\mathrm{R}$ package MASS, Venables and Ripley 2002). The latter analysis was restricted to our sweep net data (four sites in Table 1 except Bielefeld and Le Cachot).

\section{Relationship between ecology and phylogeny}

We further computed Schoener's index of co-occurrence (Schoener 1917) as

$$
C_{i j}=1-0.5 \sum_{k=1}^{n}\left|p_{i k}-p_{j k}\right|
$$

where $C$ denotes the proportional similarity between species $i$ and $j$ across $n$ sites, $p_{i k}$ is the proportion of species $i$ in sample $k$, and $p_{j k}$ is the proportion of species $j$ in sample $k$. This estimate of proportional similarity is well suited to quantify pairwise co-occurrence (Neeson and Mandelik 2014). Phylogenetic distances were derived by constructing a cladogram based on previous publications (Zhao et al. 2013, Rohner et al. 2014) and setting all branch lengths to unity. Relationships (i.e. correlations) between ecological co-occurrence and phylogenetic distance were tested by randomizing the tips of the phylogeny 999 times using the $\mathrm{R}$ package picante (Kembel et al 2010). A positive correlation between genetic and ecological distance measures would suggest that closely related species are also more prone to co-occur (Hardy 2008).

\section{Colonisation as function of dung pat age}

As interspecific variation in the timing of substrate colonization could contribute to niche differentiation as well, we were also interested in temporal succession relating to substrate (i.e. cow dung) age. Our seasonal data were hence complemented by detailed longitudinal observations of the colonization by sepsid flies of fresh dung pats. These data stem from a so far unpublished Diploma thesis of the University of Bielefeld, Germany (Püchel 1993). Dung pats were dated upon appearance and subsequently observed over 1 to 7 days. Individual females appearing on these dung pats were first fixed by putting a glass vial over them and then observing their oviposition 
Table 2. Percent average abundance of all sepsid species across all sampled seasons and years for each sampling site.

\begin{tabular}{|c|c|c|c|c|c|c|}
\hline Species & $\begin{array}{l}\text { Wolzenalp, } \\
\text { Nesslau (SG) }\end{array}$ & $\begin{array}{l}\text { Tourbière du } \\
\text { Cachot, Le } \\
\text { Cachot (NE) }\end{array}$ & $\begin{array}{l}\text { Siglistorf } \\
\text { (AG) }\end{array}$ & $\begin{array}{l}\text { Schönenboden, } \\
\text { Sörenberg (LU) }\end{array}$ & $\begin{array}{l}\text { Ziegelhütte, } \\
\text { Zürich (ZH) }\end{array}$ & $\begin{array}{c}\text { Mean across } \\
\text { sites }\end{array}$ \\
\hline Nemopoda nitidula (Fallén, 1820) & 0.00 & 0.08 & 1.02 & 0.23 & 0.36 & 0.40 \\
\hline Saltella nigripes Robineau-Desvoidy, 1830 & 0.00 & 0.00 & 0.15 & 0.00 & 5.49 & 2.32 \\
\hline Saltella sphondylii (Schrank, 1803) & 2.26 & 0.34 & 9.42 & 1.84 & 6.74 & 5.21 \\
\hline Sepsis biflexuosa Strobl, 1893 & 1.43 & 0.00 & 1.60 & 1.00 & 1.11 & 1.09 \\
\hline Sepsis cynipsea (Linnaeus, 1758) & 49.97 & 45.76 & 29.39 & 39.09 & 29.91 & 34.79 \\
\hline Sepsis duplicata Haliday, 1838 & 3.37 & 1.53 & 5.98 & 1.72 & 9.51 & 5.88 \\
\hline Sepsis flavimana Meigen, 1826 & 11.66 & 0.35 & 6.14 & 25.44 & 11.99 & 12.63 \\
\hline Sepsis fulgens Meigen, 1826 & 18.57 & 0.96 & 12.78 & 11.67 & 2.31 & 7.29 \\
\hline Sepsis luteipes Melander \& Spuler, 1917 & 0.00 & 0.33 & 1.30 & 1.22 & 0.00 & 0.56 \\
\hline Sepsis neocynipsea Melander \& Spuler, 1917 & 11.65 & 1.20 & 7.67 & 8.92 & 2.99 & 5.57 \\
\hline Sepsis nigripes Meigen, 1826 & 0.00 & 0.00 & 0.14 & 0.00 & 0.13 & 0.08 \\
\hline Sepsis orthocnemis Frey, 1908 & 0.35 & 35.81 & 2.89 & 1.15 & 0.87 & 4.94 \\
\hline Sepsis punctum (Fabricius, 1794) & 0.00 & 10.82 & 5.20 & 0.00 & 5.50 & 4.42 \\
\hline Sepsis thoracica (Robineau-Desvoidy, 1830) & 0.30 & 0.00 & 8.91 & 0.87 & 9.29 & 5.80 \\
\hline Sepsis violacea Meigen, 1826 & 0.14 & 2.81 & 4.90 & 1.31 & 0.15 & 1.59 \\
\hline Themira annulipes (Meigen, 1826) & 0.30 & 0.01 & 2.20 & 5.42 & 12.93 & 7.06 \\
\hline Themira gracilis (Zetterstedt, 1847) & 0.00 & 0.00 & 0.00 & 0.03 & 0.00 & 0.01 \\
\hline Themira leachi (Meigen, 1826) & 0.00 & 0.00 & 0.00 & 0.00 & 0.70 & 0.29 \\
\hline Themira minor (Haliday, 1833) & 0.00 & 0.00 & 0.11 & 0.09 & 0.03 & 0.05 \\
\hline Themira nigricornis (Meigen, 1826) & 0.00 & 0.00 & 0.19 & 0.00 & 0.00 & 0.04 \\
\hline
\end{tabular}

for 30 min. Once oviposition terminated, females would walk up the glass vial to be captured and later identified to species. These observation times were later categorized according to pat age (hours 1 to 7 on the first day; hours 22 to $29 \mathrm{~h}$ on the second day; thereafter only by day).

\section{Results}

\section{Seasonal patterns}

We obtained a total of 17,010 sepsid specimens, of which 8,816 were male. 95 of our 265 samples contained 20 or more specimens. Of the 28 species native to Switzerland (Rohner 2015, Rohner and Bächli 2016), 20 species were recovered in our samples at the monitored sites: 12 species of Sepsis, 5 species of Themira, 2 species of Saltella, and Nemopoda nitidula (Figs 1, 2, Table 2). Most Themira species were very rare, except $T$. annulipes, which was found in low numbers at all sites throughout the season (April - September). $N$. nitidula only occurred in Siglistorf, a northern Swiss low altitude site, in early summer, and at Le Cachot, a western, higher altitude site, in late summer, but not at the other three sites. Saltella nigripes only occurred at the Zürich site during July-September, whereas Saltella sphondylii was common at all sites throughout the season.

Of the 12 Swiss Sepsis species, S. nigripes, S. luteipes and $S$. biflexuosa were generally rare, all others more or less common at most sites (Table 2). Interestingly, the Malaise trap at Le Cachot never trapped $S$. thoracica, $S$. nigripes, $S$. duplicata, or $S$. biflexuosa, and also no $T$. annulipes. Sepsis punctum, S. violacea and S. thoraci$c a$ were present only at low altitude sites (except in the Swiss Jura at Le Cachot, where the former two species also occurred regularly). It is important to note, howev- er, that different sampling methods may catch different species at different proportions (Bährmann and Bellstedt 2012), limiting direct comparisons.

For the common species, some seasonal patterns emerged. S. cynipsea, S. orthocnemis, S. punctum, S. thoracica, S. duplicata and Saltella sphondylii were commonly observed over the entire season with a peak in summer; they can hence be classified as warm-loving. $S$. neocynipsea, $S$. violacea and $S$. fulgens peaked in spring, and $S$. flavimana (plus possibly Saltella sphondylii at low altitude) in autumn (Fig. 1). Continued activity of $S$. $f l a-$ vimana (but not Saltella sphondylii) late in the season (September) was also apparent in Püchel's (1993) seasonal data from Bielefeld, Germany.

The first three Hill numbers were highest in spring and summer and decreased towards the end of the season in autumn ( ${ }^{0} \mathrm{D}: \chi^{2}{ }_{(1)}=23.22, \mathrm{P}<0.001,{ }^{1} \mathrm{D}: \chi^{2}{ }_{(1)}=14.53, \mathrm{P}$ $<0.001,{ }^{2} \mathrm{D}: \chi_{(1)}^{2}=9.13, \mathrm{P}=0.003$; Fig. 2). That is, not only species richness, but also evenness and diversity decrease towards winter. All three indices were lower for dung piles compared to pastures and the Malaise sampling (all $\chi_{(2)}^{2} \geq 9.73, P \leq 0.008$, Fig. 2 ). In contrast to the findings reported in Rohner et al (2015), diversity was generally higher at low latitude sites $\left({ }^{0} \mathrm{D}: \chi_{(1)}^{2}=2.95, \mathrm{P}=\right.$ $0.086,{ }^{1} \mathrm{D}: \chi_{(1)}^{2}=12.53, \mathrm{P}<0.001,{ }^{2} \mathrm{D}: \chi_{(1)}^{2}=11.55, \mathrm{P}<$ $0.001)$. Canonical variate analyses also revealed community structure to vary significantly over the season $\left(\chi_{(1)}^{2}=\right.$ $0.14, \mathrm{P}=0.001$, Fig. 3 ) and between pastures and dung piles $\left(\chi_{(1)}^{2}=0.37, \mathrm{P}=0.001\right)$.

\section{Relationship between ecology and phylogeny}

The correlation between species co-occurrence and their phylogenetic distance across all samples revealed significant under-dispersion, with an observed correlation 


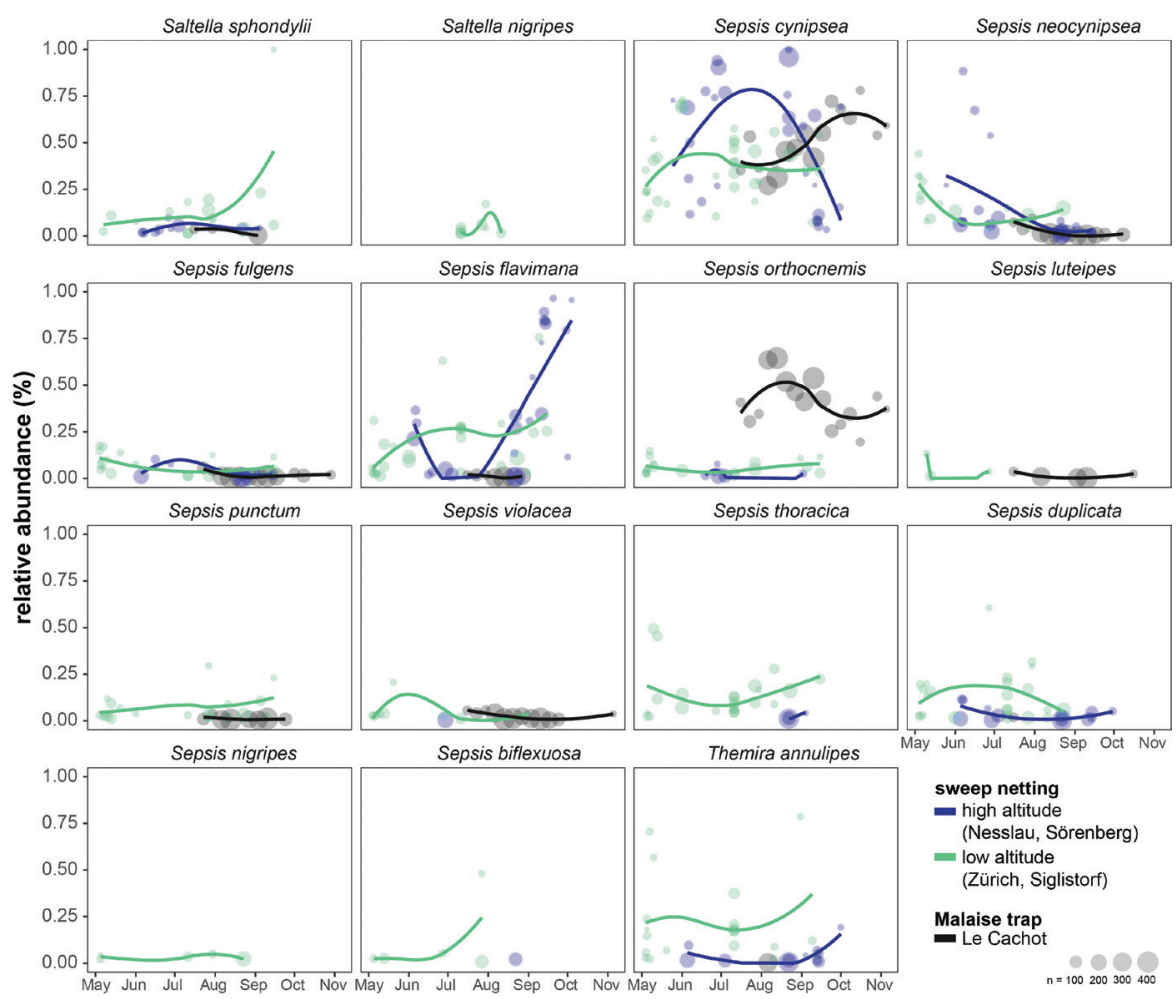

Figure 1. Relative abundance of males of different sepsid species across the season on pastures (all years pooled). Patterns are indicated separately for high (blue) and low (green) altitude sites. Species trapped in a Malaise trap are shown in black. Point size is proportional to the total number of males contained in the respective sample.
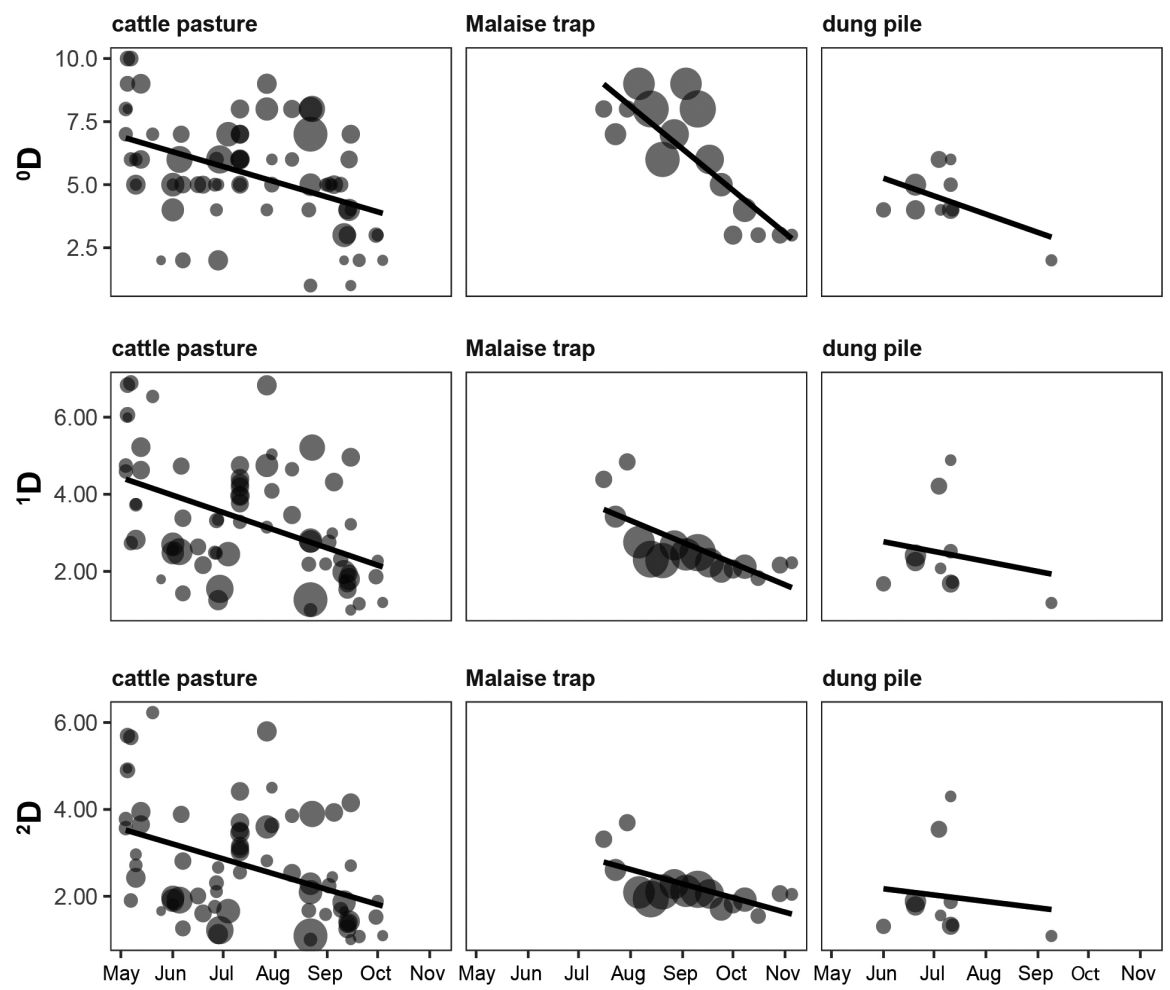

Malaise trap

dung pile
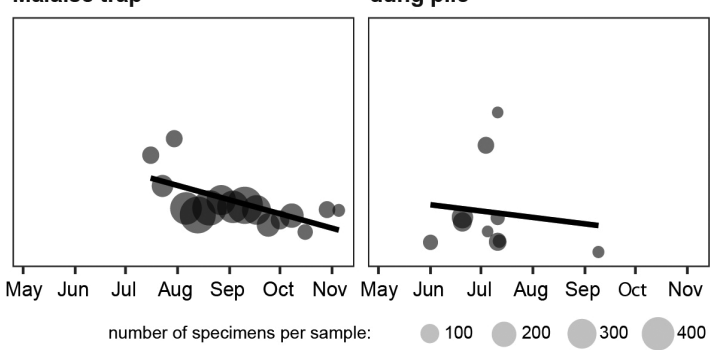

Figure 2. Seasonal patterns of species diversity, expressed by the first three Hill indices, for sepsid communities captured by sweep netting on cow pastures, dung piles or Malaise capturing in a peat bog. ${ }^{0} \mathrm{D}$ equals species richness, ${ }^{1} \mathrm{D}$ represents the exponential Shannon entropy (evenness) that can be interpreted as the number of typical species, while ${ }^{2} \mathrm{D}$ resembles the reciprocal form of the Gini-Simpson Index that relates to the number of highly abundant species. We only plotted samples with 20 or more individuals (all years combined). The size of the points is proportional to the number of individuals present in the sample. 


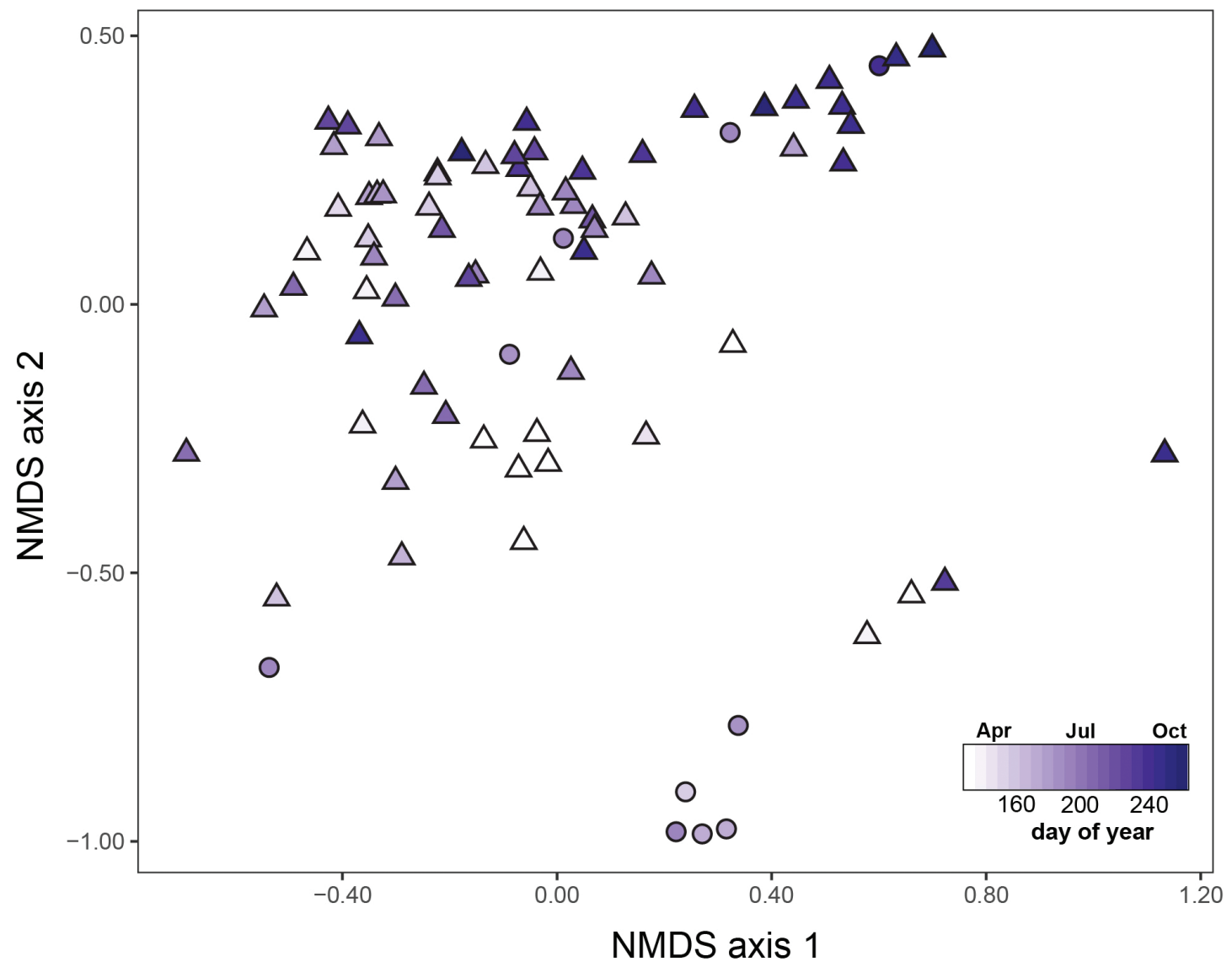

Figure 3. Non-metric multidimensional scaling (NMDS) visualizing seasonal variation in species composition as well as differences between cattle pastures (triangles) and dung piles (circles). The smaller the distance between two samples, the greater their similarity.
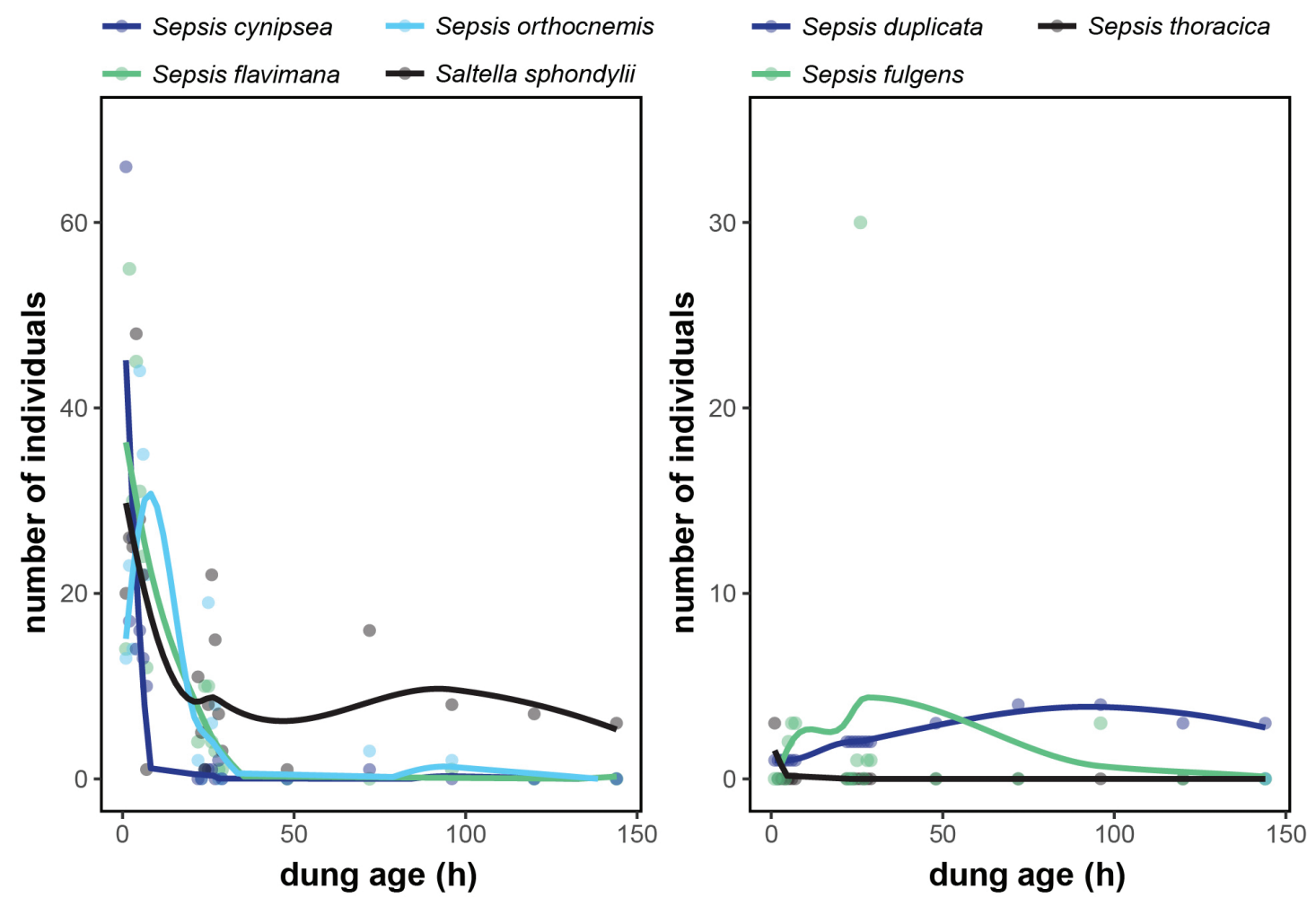

Figure 4. Number of individuals of seven common sepsid species as a function of dung age (in hours (h)). While S. cynipsea, flavimana and orthocnemis are disproportionally often observed on fresh dung, S. duplicata and Saltella sphondylii gain in relative abundance over time. (Note the different scaling of the y-axes; data from Püchel 1993; S. duplicata data only qualitative.) 
of $r=-0.46$ when using the (extended) phylogeny of Zhao et al. (2013). Hence, close relatives were more prone to be found in the same sample than expected by chance.

\section{Colonisation as function of dung pat age}

Species clearly differ in their absolute (as well as relative) abundance as a function of cow pat age. The 1991 data collected in Bielefeld show S. cynipsea, S. flavimana and $S$. orthocnemis to be particularly abundant on fresh cow dung, while $S$. duplicata and Saltella sphondylii were common throughout the first 7 days (Fig. 4). Accordingly, the species community varied with time (canonical correspondence analysis: $\chi_{(18)}^{2}=0.19, \mathrm{P}=0.038$ ). Note that $S$. duplicata often enters dung beetle tunnels when dung is dry. This behaviour makes it very difficult to quantify the species' occurrence and oviposition; therefore its abundance is likely underestimated in this dataset.

\section{Discussion}

Temporal niche partitioning represents a major axis of species differentiation that can allow for and maintain species diversity, particularly in ephemeral habitats such as vertebrate dung (Hanski and Cambefort 1991). We here found seasonal variation in species occurrence, diversity and community composition, suggesting temporal, presumably thermal niche differentiation among closely related species. Additionally, detailed longitudinal data show pronounced species turnover of sepsids on individual cowpats, suggesting temporal segregation on a much finer scale relating to desiccation, in addition to broad phenological differences. We in the following discuss the implications of temporal and thermal niche differentiation for our understanding of the natural history of black scavenger flies.

The seasonal distribution patterns of a total of 20 (16 of them common) Swiss sepsid fly species north of the Alps (Mittelland) agree well with their distribution and thermal niches previously inferred from their spatial distribution in Switzerland (Rohner et al. 2015) and Central Europe as a whole (Pont and Meier 2002, Ozerov 2005). Along with Nemopoda nitidula, which we only found in early summer at one northern Swiss low altitude site (Siglistorf), and Saltella nigripes, which only occurred at the Zürich site in late summer, Sepsis nigripes, $S$. luteipes, S. biflexuosa, and most Themira species were generally very rare around cattle pastures. Only T. annulipes was found in low numbers at most sites throughout the season (April - September). Themira spp. are known to be often specialized on bird (waterfowl) excrements (Pont and Meier 2002), so our pasture sites may simply be the wrong habitats to find them.

Saltella sphondylii is cosmopolitan in Switzerland, though generally more common at lower altitudes. Of the 12 Sepsis spp. reported in Switzerland (Haenni 1998; Rohner et al. 2014, Rohner 2015; Rohner and Bächli 2016), which are also common in northern Germany (Bielefeld: Püchel 1993), 9 were common at low altitudes, with only 5 of them also common at higher altitudes above $1000 \mathrm{~m}$. Sepsis punctum, $S$. violacea and $S$. thoracica were almost exclusively present at low altitude sites (ca. $500 \mathrm{~m}$ ) but rarely if ever observed above $1000 \mathrm{~m}$. At the special site Le Cachot in the Swiss Jura (ca. $1100 \mathrm{~m}$ ) sampled with a Malaise trap in 1973 (Haenni and Matthey 1984), S. orthocnemis was extraordinarily common, for unknown reasons, and $S$. punctum and $S$. violacea also regularly occurred, whereas $S$. thoracica, S. nigripes and S. biflexuosa were definitely absent. The Malaise trap, however, was not placed directly on a pasture, and is therefore not directly comparable to the other samples, as this type of trap likely catches moving or migrating rather than reproducing or foraging individuals (Bährmann and Bellstedt 2012).

For the common species, some seasonal patterns emerged in the lowlands: $S$. cynipsea, $S$. orthocnemis, $S$. punctum, S. thoracica, and S. duplicata, as well as Saltella sphondylii, were all commonly present over the entire season with a peak in summer. Presupposing that these phenological patterns reflect thermal preferences, the latter can therefore be classified as warm-loving or warm-adapted (as is definitely the case for $S$. thoracica: Busso and Blanckenhorn 2018). S. neocynipsea, S. fulgens and S. violacea peaked in spring, and S. flavimana (and lowland Saltella sphondylii) in autumn (Fig. 1). Save S. violacea, the latter species are also common at highland sites in the Alps and can therefore be classified as cold-loving or cold-adapted (Rohner et al. 2015). Correspondingly, S. fulgens, S. violacea and $S$. flavimana also abound at higher latitudes (Bährmann and Bellstedt 2012; Pont and Meier 2002). As $S$. orthocnemis and S. punctum, S. violacea appears to be found most everywhere, though in low numbers, some local abundance notwithstanding (viz. Le Cachot); the Swiss Mittelland may actually mark $S$. violacea's southern distribution edge (Pont and Meier 2002). S. neocynipsea, in contrast, is known to be rare in Europe and restricted to higher altitudes, whereas this species is common in North America, even in warm lowlands such as Arizona (pers. obs.), where it apparently takes the ecological niche that S. cynipsea has in Europe (Pont 1979, Rohner et al. 2015, 2016, Giesen et al. 2017). Though repeatedly reported in Britain even in the lowlands, but not in Scandinavia (Pont 1979, Pont and Meier 2002), our own experience is that $S$. neocynipsea is difficult if not impossible to find in Europe except in mountainous regions such as Asturias (Spain), Cevennes (France), or the (Swiss) Alps, where it can be locally abundant (Rohner et al. 2014, 2015, 2016), a somewhat puzzling distribution pattern. The sister species $S$. neocynipsea and S. cynipsea coexist and meet regularly at our Sörenberg site and throughout the Swiss Alps (e.g. Rohner et al 2015, Rohner 2015, Rohner and Bächli 2016). These two species hybridize readily in the laboratory, though hybridization is apparently prevented in nature by behavioural incompatibility (Giesen et al. 2017, 2018).

Rohner et al. (2015) demonstrated greater sepsid species richness at higher altitudes in the Swiss Alps. Al- 
though diversity tended to be lower at high altitudes here, species diversity was highest in spring and summer and dropped off towards the end of the season in autumn (Fig. 2). This result is unsurprising given that S. flavima$n a$ is the only species with a phenology peaking late in the season (see also Püchel 1993), and knowing that Sepsis spp. in general seem to overwinter as adults, thus being ready to reproduce early in the season (Blanckenhorn 1998, Zeender 2015).

Given that members of the same taxonomic group are expected to use similar resources, and thus to compete most intensely, such high species diversity is intriguing, particularly in an ephemeral habitat that is characterized by severe intra- and interspecific competition for food and space (e.g. Jiri et al 2017, Papp 1992, 2007, Hanski and Cambefort 1991). Intraspecific resource competition has been demonstrated repeatedly in sepsids (Rohner et al 2016, Busso and Blanckenhorn 2018), and yet unpublished laboratory data provide direct evidence for some larval competition between S. cynipsea and S. punctum. Still, we found here and elsewhere (Rohner et al. 2015; Rohner and Bächli 2015) that more closely related species are more prone to co-occur. In order to evade direct competition, species are therefore expected to differ in aspects other than phenology. In this context, temporal succession in the colonization of dung pats has been suggested, as some species seem to be associated with particularly fresh (e.g. S. cynipsea) or older cow dung (e.g. S. duplicata or S. fulgens; Jiri et al. 2017, Pont and Meier 2002, Rohner et al. 2015). Based on Püchel's (1993) work, we could here confirm this (Fig. 4). Niche differentiation may thus be revealed at much finer temporal scales. Furthermore, specialization on specific substrates (i.e. cattle dung versus excrements of other large vertebrates), or spatial separation within substrates, may account for the co-occurrence of species within the genus Sepsis. However, even if species dwell and reproduce in the same substrate simultaneously, it is unclear whether larvae actually feed on the same compounds. Sepsids are presumed to filter-feed on small particles such as fungi and bacteria (Pont and Meier 2002), but whether different species or different larval stages feed on different nutrients is unknown. Further anecdotal evidence suggests that some species use a very broad range of substrates (e.g. S. fulgens is found on cow, pig, chicken dung as well as compost: Pont and Meier 2002), while other are highly specialized (Sepsis duplicata is mostly found on dry cow dung). In addition to different substrate preferences, such a specialist - generalist continuum may further facilitate coexistence. Both niche differentiation by substrate choice and specialization, as well as fine-scale temporal succession within cattle pastures, hence should be studied further.

Our finding that species that regularly co-occur tend to be more closely related than expected by chance can also be interpreted as evidence against a strong influence of competitive exclusion, i.e. that other mechanisms, such as environmental filtering, may be more important. However, this assumes phylogenetic inertia of those traits related to competition. Although body size and de- velopment times show phylogenetic signals in Sepsidae (e.g. Rohner et al. 2016), behavioural traits evolve very rapidly across species (Ang et al. 2008, Puniamoorthy et al. 2009, Puniamoorthy 2014, Tan et al. 2011). Given our lack of data on larval physiology and nutritional ecology, we cannot yet link co-occurrence to interspecific variation (or population differentiation within species) in the larval ecology of sepsids, but this clearly warrants further scrutiny.

\section{Conclusions}

The seasonal distribution patterns of Swiss sepsid fly species on Swiss cow pastures north of the Alps agree well with their previously documented spatial distribution patterns (Ozerov 2005, Pont and Meier 2002, Rohner et al. 2014, 2015). Nemopoda nitidula, Saltella nigripes, most Themira spp. (except T. annulipes), Sepsis nigripes, S. luteipes and $S$. biflexuosa are generally rare on Swiss dairy cow pastures (see also Rohner et al. 2015). Sepsis punctum, $S$. violacea and $S$. thoracica were absent to rare at high altitude sites $>1000 \mathrm{~m}$ (except the Jura). Abundances of the more common and widespread species throughout Europe (S. cynipsea, S. orthocnemis, S. punctum, S. thoracica, S. duplicata, Saltella sphondylii) peaked in summer, whereas species also common at high latitudes peaked in spring (S. neocynipsea, $S$. fulgens, $S$. violacea) or autumn (S. flavimana). Phenology and thermal adaptation alone are however unlikely to explain the high levels of species diversity and coexistence. As closely related species are more likely to be present in a sample, temporal succession and substrate specialization may limit direct competition and enable coexistence even of close relatives.

\section{Acknowledgements}

This work was supported over the years by the University of Zurich, the Zoological Museum of Zurich, and several grants from the Swiss National Science Foundation, most recently grant no. 31003A_143787.

\section{References}

Addo-Bediako A, Chown SL, Gaston KJ (2000) Thermal tolerance, climatic variability and latitude. Proceedings of the Royal Society B-Biological Sciences 267: 739-745. https://doi.org/10.1098/rspb.2000.1065

Ang YC, Puniamoorthy J, Pont AC, Bartak M, Blanckenhorn WU, Eberhard WG, Puniamoorthy N, Silva V, Munari L, Meier R (2013) Sepsidnet: A plea for digital reference collections and other science-based digitization initiatives in taxonomy. Systematic Entomology 38: 637-644. https://doi.org/10.1111/syen.12015

Ang, YC, Puniamoorthy N, Meier R (2008) Secondarily reduced foreleg armature in Perochaeta dikowi sp.n. (Diptera: Cyclorrhapha: Sepsidae) due to a novel mounting technique. Systematic Entomology 33(3): 552-559. https://doi.org/10.1111/j.1365-3113.2008.00422.x 
Bährmann R (1993) Zum Vorkommen der Sepsidae in unterschiedlichen Rasenökosystemen Thüringens. Beiträge zur Entomologie 43: 97-113.

Bährmann R, Bellstedt R (2012) Neuere öko-faunistische Untersuchungen an Schwingfliegen (Insecta: Diptera: Brachycera-Acalyptratae: Sepsidae) Thüringens. Thüringer Faunistische Abhandlungen 17: 93-110.

Berger D, Postma E, Blanckenhorn WU, Walters RJ (2013) Quantitative genetic divergence and standing genetic (co)variance in thermal reaction norms along latitude. Evolution 67: 2385-2399. https://doi. org/10.1111/evo.12138

Blanckenhorn WU (2009) Causes and consequences of phenotypic plasticity in body size: the case of the yellow dung fly (Diptera: Scathophagidae). In: Whitman DW, Ananthakrishnan TN (Eds) Phenotypic plasticity of insects: Mechanisms and consequences. Science Publishers, Strixton, 313-366. https://doi.org/10.1201/b10201-11

Blanckenhorn WU, Puniamoorthy N, Schäfer MA, Scheffczyk A, Römbke J (2013) Standardized laboratory tests with 21 species of temperate and tropical sepsid flies confirm their suitability as bioassays of pharmaceutical residues (ivermectin) in cattle dung. Ecotoxicology and Environmental Safety 89: 21-28. https://doi.org/10.1016/j.ecoenv.2012.10.020

Blanckenhorn WU, Bauerfeind SS, Berger D, Davidowitz G, Fox CW, Guillaume F, Nakamura S, Nishimura K, Sasaki H, Stillwell CR, Tachi T, Schäfer MA (2018) Replicated latitudinal life-history clines on three continents in the widespread yellow dung fly. Ecography 41. https://doi.org/10.1111/ecog.03752 [in press]

Bowsher JH, Nijhout HF (2007) Evolution of novel abdominal appendages in a sepsid fly from histoblasts, not imaginal discs. Evolution \& Development 9: 347-354.https://doi.org/10.1111/j.1525-142X.2007.00171.x

Busso JP, Blanckenhorn WU (2018) Climatic factors shaping plastic trade-offs in the polyphenic black scavenger fly Sepsis thoracica (Diptera: Sepsidae). Journal of Biogeography 45: 593-603. https:// doi.org/10.1111/jbi.13140

Cárdenas RE, Basset Y, Gilbert F (2016) Fine-scale climatic variation drives altitudinal niche partitioning of tabanid flies in a tropical montane cloud forest, Ecuadorian Chocó. Insect Conservation and Diversity 9: 87-96. https://doi.org/10.1111/icad.12146

Chesson P (2000) Mechanisms of maintenance of species diversity. Annual Review of Ecology and Systematics 31: 343-366. https://doi. org/10.1146/annurev.ecolsys.31.1.343

Danks HV (1987) Insect dormancy: an ecological perspective. Biological Survey of Canada, Ottawa.

Deutsch CA, Tewksbury JJ, Huey RB, Sheldon KS, Ghalambor CK, Haak DC, Martin PR (2008) Impacts of climate warming on terrestrial ectotherms across latitude. Proceedings of the National Academy of Sciences of the United States of America 105: 6668-6672. https://doi.org/10.1073/pnas.0709472105

Eberhard WG (2001) Species-specific genitalic copulatory courtship in sepsid flies (Diptera, Sepsidae, Microsepsis) and theories of genitalic evolution. Evolution 55: 93-102. https://doi. org/10.1111/j.0014-3820.2001.tb01275.x

Elton CS (1946) Competition and the structure of animal communities. Journal of Animal Ecology 15: 54-68. https://doi.org/10.2307/1625

Gaston KJ, Blackburn TM (2000) Pattern and Process in Macroecology. Blackwell Science. https://oi.org/10.1002/9780470999592

Gaston KJ, Chown SL, Evans KL (2008) Ecogeographical rules: elements of a synthesis. Journal of Biogeography 35: 483-500. https:// doi.org/10.1111/j.1365-2699.2007.01772.x
Gotelli NJ, Chao A (2013) Measuring and estimating species richness, species diversity, and biotic similarity from sampling data. In: Levin SA (Ed.) Encyclopedia of Biodiversity, Vol. 5, Academic Press, Waltham, Massachusetts, 195-211. https://oi.org/10.1016/ B978-0-12-384719-5.00424-X

Giesen A, Schäfer MA, Blanckenhorn WU (2017) Behavioural mechanisms of reproductive isolation between two hybridizing dung fly species (Sepsis cynipsea \& S. neocynipsea: Diptera: Sepsidae). Animal Behaviour 132: 155-166. https://doi.org/10.1016/j.anbehav.2017.08.008

Giesen A, Schäfer MA, Blanckenhorn WU (2018) Patterns of postzygotic isolation between two closely related sepsid fly species (Sepsis cynipsea and S. neocynipsea; Diptera: Sepsidae). Journal of Zoological Systematics and Evolutionary Research. https://doi. org/10.1111/jzs.12239 [in press]

Haenni J-P (1998) Sepsidae. In: Merz B, Baechli G, Haenni J-P, Gonseth Y (Eds) Diptera - Checklist. Fauna Helvetica, Vol. 1. Schweizerische Entomologische Gesellschaft, Neuchâtel, 249-250.

Haenni J-P, Matthey W (1984) Utilisation d'un piège d'interception (tente malaise) pour l'étude entomologique d'une tourbière du HautJura. I, Introduction et résultats généraux. Bulletin de la Société Neuchâteloise des Sciences Naturelles 107: 111-122. http://doi. org/10.5169/seals-89219

Hanski I, Cambefort Y (1991) Dung Beetle Ecology. Princeton, Princeton University Press. https://doi.org/10.1515/9781400862092

Hardy OJ (2008) Testing the spatial phylogenetic structure of local communities: statistical performances of different null models and test statistics on a locally neutral community. Journal of Ecology 96: 914-926. https://doi.org/10.1111/j.1365-2745.2008.01421.x

Hill MO (1973) Diversity and evenness: A unifying notation and its consequences. Ecology 54: 427-431. https://doi.org/10.2307/1934352

Holt RD (2009) Bringing the Hutchinsonian niche into the 21st century: Ecological and evolutionary perspectives. Proceedings of the National Academy of Sciences 106: 19659-19665. https://doi. org/10.1073/pnas.0905137106

Ingram KK, Laamanen T, Puniamoorthy N, Meier R (2008) Lack of morphological coevolution between male forelegs and female wings in Themira (Sepsidae: Diptera: Insecta). Biological Journal of the Linnean Society 93: 227-238. https://doi.org/10.1111/j.10958312.2007.00922.x

Jann P, Blanckenhorn WU, Ward PI (2000) Temporal and microspatial variation in the intensities of natural and sexual selection in the yellow dung fly Scathophaga stercoraria. Journal of Evolutionary Biology 13: 927-938. https://doi.org/10.1046/j.1420-9101.2000.00230.x

Jiri SFX, Sulakova H, Konvicka M (2017) Temporal segregations in the surface community of an ephemeral habitat: Time separates the potential competitors of coprophilous Diptera. Entomological Science 20: 111-121. https://doi.org/10.1111/ens.12240

Kembel SW, Cowan PD, Helmus MR, Cornwell WK, Morlon H, Ackerly DD, Blomberg SP, Webb CO (2010) Picante: R tools for integrating phylogenies and ecology. Bioinformatics 26:1463-1464. https://doi.org/10.1093/bioinformatics/btq166

Kumar S, Stecher G, Tamura K (2016) MEGA7: Molecular Evolutionary Genetics Analysis version 7.0 for bigger datasets. Molecular Biology and Evolution 33: 1870-1874. https://oi.org/10.1093/ molbev/msw054

Lei Z, Ang SHA, Srivathsan A, Su KFY, Meier R (2013) Does better taxon sampling help? A new phylogenetic hypothesis for Sepsidae 
(Diptera: Cyclorrhapha) based on 50 new taxa and the same old mitochondrial and nuclear markers. Molecular Phylogenetics and Evolution 69: 153-64. https://doi.org/10.1016/j.ympev.2013.05.011

Levine JM, HilleRisLambers J (2009) The importance of niches for the maintenance of species diversity. Nature 461: 254-257. https://doi. org/10.1038/nature08251

Loboda S, Savage J, Buddle CM, Schmidt NM, Høye TT (2018) Declining diversity and abundance of High Arctic y assemblages over two decades of rapid climate warming. Ecography 41: 265-277. https://doi.org/10.1111/ecog.02747

Oksanen J, Blanchet FG, Friendly M, Kindt R, Legendre P, McGlinn D, Minchin PR, O’Hara LB, Simpson GL, Solymos P, Stevens MHM, Szoecs E, Wagner H (2018) vegan: Community Ecology Package. R package version 2.5-3. https://CRAN.R-project.org/package=vegan

Neeson TM, Mandelik Y (2014) Pairwise measures of species co-occurrence for choosing indicator species and quantifying overlap. Ecological Indicators 45: 721-727. https://doi.org/10.1016/j. ecolind.2014.06.006

Ozerov A (2005) World catalogue of the family Sepsidae (Insecta: Diptera). Zoologicheskie Issledovania (Zoological Studies) 8: 1-74.

Papp L (1992) Fly Communities in Pasture Dung - Some Results and Problems (Diptera). Acta Zoologica Hungarica 38(1-2): 75-88.

Papp L (2007) A study of the cow pat Diptera on the Hortobágy, Hungary. Folia Entomologica Hungarica 68: 123-135.

Parker GA (1970) Reproductive behaviour and nature of sexual selection in Scatophaga stercoraria L (Diptera Scatophagidae). 1. Diurnal and seasonal changes in population density around site of mating and oviposition. Journal of Animal Ecology 39: 185-204. https:// doi.org/10.2307/2895

Pont AC (1979) Sepsidae. Diptera, Cyclorrhapha, Acalyptrata. In: Fitton MG (Ed.) Handbook for the Identification of British Insects, Vol X, Part 5. Royal Entomological Society, London, 1-35.

Pont AC (1987) Provisional atlas of the Sepsidae (Diptera) of the British Isles. Biological Records Centre Institute of Terrestrial Ecology, 1-34.

Pont AC, Meier R (2002) The Sepsidae (Diptera) of Europe. Fauna Entomologica Scandinavica 37: 1-221.

Püchel F (1993) Untersuchungen über die Besiedlung von Kuhdung durch Sepsiden (Diptera). (Diploma Thesis) University of Bielefeld, Germany.

Puniamoorthy N, Ismail MRB, Tan DSH, Meier R (2009) From kissing to belly stridulation: comparative analysis reveals surprising diversity, rapid evolution, and much homoplasy in the mating behaviour of 27 species of sepsid flies (Diptera: Sepsidae). Journal of evolutionary Biology 22: 2146-2156. https://doi.org/10.1111/j.14209101.2009.01826.x

Puniamoorthy N, Blanckenhorn WU, Schäfer MA (2012) Differential investment in pre- versus post-copulatory sexual selection reinforces a cross-continental reversal of sexual size dimorphism in Sepsis punctum (Diptera: Sepsidae). Journal of Evolutionary Biology 25: 2253-2263. https://doi.org/10.1111/j.1420-9101.2012.02605.x

Puniamoorthy N, Schäfer MA, Römbke J, Meier R, Blanckenhorn WU (2014) Ivermectin sensitivity is an ancient trait affecting all ecdysozoa but shows phylogenetic clustering among sepsid flies. Evolutionary Applications 7: 548-554. https://doi.org/10.1111/eva.12152

Puniamoorthy N (2014) Behavioural barriers to reproduction may evolve faster than sexual morphology among populations of a dung fly (Sepsidae). Animal Behaviour 98: 139-148. https://doi. org/10.1016/j.anbehav.2014.10.005
Rohner PT, Puniamoorthy N, Ang Y, Lei Z, Blanckenhorn WU, Meier R (2014) Genetic data confirm the species status of Sepsis nigripes, Meigen 1826 (Diptera: Sepsidae) and adds one species to the Alpine fauna while questioning the synonymy of Sepsis helvetica, Munari 1985. Invertebrate Systematics 28: 555-563. https://doi.org/10.1071/IS14023

Rohner PT, Bächli G (2016) Faunistic data of Sepsidae (Diptera) from Switzerland and additional countries including the first Swiss record of Meroplius fukuharai (Iwasa, 1984). Mitteilungen der Schweizerischen Entomologischen Gesellschaft 89: 237-260.

Rohner PT, Bächli G, Pollini Paltrinieri L, Duelli P, Obrist MK, Jochmann R, Blanckenhorn WU (2015) Distribution, diversity gradients and Rapoport's elevational rule in the black scavenger flies of the Swiss Alps (Diptera: Sepsidae). Insect Conservation and Diversity: https://doi.org/10.1111/icad.12114

Rohner PT (2015) An updated checklist of the Sepsidae (Diptera) of Switzerland, including the first record of Themira superba (Haliday, 1833). Mitteilungen der Schweizer Entomologischen Gesellschaft 88: 371-378.

Rohner PT, Blanckenhorn WU, Puniamoorthy N (2016) Sexual selection on male size drives the evolution of male-biased sexual size dimorphism via the prolongation of male development. Evolution 70: 1189-1199. https://doi.org/10.1111/evo.12944

Rohner PT, Pitnick S, Blanckenhorn WU, Snook RR, Bächli G, Lüpold S (2018) Global macroecology of size, sexual size dimorphism, dispersal and range size in fruit flies (Diptera: Drosophilidae). Ecography 41. https://doi.org/10.1111/ecog.03382 [in press]

Roy J, Blanckenhorn WU, Rohner PT (2018) Life history traits along a latitudinal cline in European Sepsis fulgens. Oecologia. https://oi. org/10.1007/s00442-018-4166-7 [in press]

Schoener TW (1970) Nonsynchronous spatial overlap of lizards in patchy habitats. Ecology 51: 408-418. https://doi.org/10.2307/1935376

Shimadzu H, Dornelas M, Henderson PA, Magurran AE (2013) Diversity is maintained by seasonal variation in species abundance. BMC Biology 11(1): 98. https://doi.org/10.1186/1741-7007-11-98

Tan DSH, Ng SR, Meier R (2011) New information on the evolution of mating behaviour in Sepsidae (Diptera) and the cost of male copulations in Saltella sphondylii. Organisms Diversity \& Evolution 11(4): 253-261. https://doi.org/10.1007/s13127-011-0054-2

Tauber MJ, Tauber CA, Masaki S (1986) Seasonal adaptations of insects. Oxford University Press, Oxford.

Tilman D (1982) Resource Competition and Community Structure. Princeton Univ.

Webb CO, Ackerly DD, McPeek MA, Donoghue MJ (2002) Phylogenies and community ecology. Annual Review of Ecology and Systematics 33: 475-505. https://doi.org/10.1146/annurev.ecolsys.33.010802.150448

Venables WN, Ripley BD (2002) Modern Applied Statistics with S. Fourth Edition. Springer, New York. https://doi.org/10.1007/978-0387-21706-2

Zeender V (2015) Effects of temperature, photoperiod and developmental stage on diapause in black scavenger flies (Diptera: Sepsidae). (MSc Thesis) University of Zurich, Switzerland.

Zhao L, Ang ASH, Srivathsan A, Su KFY, Meier R (2013) Does better taxon sampling help? A new phylogenetic hypothesis for Sepsidae (Diptera: Cyclorrhapha) based on 50 new taxa and the same old mitochondrial and nuclear markers. Molecular Phylogenetics and Evolution 69: 153-164. https://doi.org/10.1016/j. ympev.2013.05.011 